house was a centre of hospitality for soldiers stationed in the neighbourhood. Some of the friendships formed then remained to the end.

The second tragedy of his life occurred in the summer of 1937 , a few months before his retiral, when he became afflicted with heart disease. After a long and arduous struggle he could well look back with satisfaction on what he had accomplished and was entitled to look forward to a peace and freedom in which he might indulge the sporting instinct with which he was endowed and the interest in national history which he had cultivated. Nature, however, had determined otherwise. Deprived of physical energy he tried in vain to lead the life that appealed to his tastes. Even moderate exertion was beyond his strength. Sustained by a fortitude which stood him in good stead in the battle of life, he bore with resignation the trials of a suffering illness and passed away on June 2, I939.

In the sombre atmosphere of the hills he loved so well his remains were laid to rest beside the graves of his fathers in the Spittal of Glenshee. His name will remain at the scene of his labour at Hillside, and those who knew him well will cherish the memory of a fine nature untarnished by selfishness or petty jealousy, courageous in adversity and shedding a glow of happiness and serenity on those around him. He was truly a man whom to know was to love and to honour.

IVY MACKENZIE.

\title{
LIEUT.-Col. THOMAS EDWARD KNOWLES STANSFIELD, C.B.E., M.B.Edin. (LATE R.A.M.C.).
}

Although it is some eighteen years since Col. Stansfield retired from the practice of his profession and for more than half of that time he had lived abroad, the force of his enthusiasm and work is by no means spent. Not a few of the present-day arrangements for treatment in mental hospitals in this country directly or indirectly owe their origin to his administrative genius ; some were devised by him and others, which either had been suggested to him or which he had observed abroad and whose importance he had been quick to see, owe their adoption, secured sometimes in the face of opposition and misunderstanding, to the forcefulness of his drive and to a strength and tenacity of purpose and decision which to the end were characteristic of him.

It therefore is only fitting that in recording his death, which, after some months of illness, took place in Paris, on February I9, I939, some memories of his work should be revived, not only in justice to his efforts, but because they won for themselves a definite place in the history of psychological medicine.

Stansfield's decision to enter the medical profession was taken later than is usual. Indeed, it is not certain what studies, arts or science, he pursued during the one year (I884-5) he spent at Owen's College, Manchester, before 
he went up to Edinburgh, where, at the age of 27 , he graduated M.B. in I889. He had a bent towards pathology and, before coming down, he for some months had held a post in that department of the Royal Infirmary.

It was just about this time that much increased attention was being given to the pathology of mental disorders, the hub and home of which conspicuously had been, and still was, the West Riding Asylum at Wakefield. In I889 the London County Council came into being, and, as part of their newly established Asylums Department, they had inherited a scheme for the erection of a new mental hospital (Claybury); within the latter's curtilage, and only six years ahead (I895) and backed by the powerful advocacy of Sir William Collins, who happily is still with us, there was established the Central Laboratory for the London mental hospitals, with the late Sir Frederick Mott as its Director. Among the other institutions taken over by the Council was Banstead Asylum, opened in 1877 for the County of Middlesex and designed for I,700 so-called chronic cases of insanity : in more than one way it had realized and demonstrated the evils of an institution designed to admit only patients transferred from other mental hospitals, and it had under consideration the provision (effected in 1895) of wards for recent cases. With the pathology of mental disorders so much to the fore, in March of 1890 there was created at Banstead the post of "Fourth Assistant Medical Officer and Pathologist" ; really that of junior assistant with an additional salary for the pathological work, which was mainly that of responsibility for post-mortem examinations : and hitherto, instead of "Pathologist" this junior medical posițion had had as its suffix " and Dispenser".

If the title "Pathologist", as used here, did not connote in fact much, it at least was a sign of the times. It was a part of the advertisement for the position which specially attracted Stansfield's notice, and no doubt the post he had been holding in Edinburgh materially helped him to become the first occupant of this new post at Banstead.

Without any previous thought of taking up mental hospital work, his interest in it was quickly roused; indeed, it became absorbing, especially upon its administrative side. It was far from limited to that aspect, however ; and two items of his work deserve special mention at this foint. Fresh from Edinburgh, where he had been accustomed to see routine appeal to the aid of the laboratory, either in clinical diagnosis or in extension of post-mortem work and where, too, as a clinical clerk in the wards, he had been subjected to a rigid discipline in the mode of note-taking at the bedside (histories and the results of physical examination, with emphasis on the importance of records of negative findings), it struck him as quite anomalous that the big institution in which he now found himself should be without a laboratory ; and, again, that clinical notes should be entered in case-books kept in offices far distant from the wards and made from material which either had been committed temporarily to memory or had been jotted down on scraps of paper or, at 
at best, in a rough pocket note-book. He was fortunate that at the head of the hospital was one of the most distinguished superintendents of the day, who also both lectured at " Bart.'s " and examined in " Mental Physiology " at the University of London for the M.D. degree-the late Dr. T. Claye Shaw, F.R.C.P. The latter, only too ready to give rein and scope to enthusiasm, was able to set aside a small room and to get it equipped as the laboratory which, though humble as compared with modern requirements, has been the scene of good work. He approved, too, of Stansfield's desire to have provided in every ward a stoutly bound note-book for the use of the medical officer. In these books, each of substantial size, the doctors in future could write their notes, either at the bed-side or vis-ä-vis the patient in perhaps a corner of the day-room (there were no clinical rooms); and later on in the day these books were conveyed to one of the offices to be copied, by the Dispenser, into the statutory case-books. This innovation, simple enough in itself, was the forerunner of the loose-leaf system of clinical records as instituted several years later at Bexley which, with or without modification, has spread to almost every mental hospital in the country and which, far from being just a piece of clerical administration, embodies important medical and other scientific principles.

Claybury, projected as the fourth asylum for Middlesex, was opened in I892-3, in fact as the fifth for the newly constituted administrative County of London. The sixty-eighth of the public asylums for England and Wales, it was the first ever to have been planned and opened for 2,000 patients; it marked the zenith of the skill of its architect, the late Mr. G. T. Hine, in designing and in the construction of what perhaps may be described best as the all-under-one-roof type of mental hospital ; it was hailed with interest in many countries; and, despite the passing of nearly fifty years, it still well repays a visit. In March of $\mathrm{I} 893$, Dr. Stansfield was transferred to Claybury as First Assistant Medical Officer.

At the age of $3 \mathbf{I}$ and with no more than three years mental hospital experience, to find himself in such an unique position of vantage was indeed a stroke of fortune. True, circumstances had helped him; within twenty months of his joining at Banstead he (October, I89I) had been promoted to be Second Assistant; he was on terms of friendship with the steward there (Mr. F. Alderton), an experienced and much trusted official who had been at Banstead since its equipment eighteen years before and who a few months previously had been transferred to Claybury in a similar capacity; and of special help to him was the fact that, until the appointment of Sir Robert Armstrong-Jones, it had been to his own chief, Dr. Claye Shaw, that the Committee had turned for advice upon important points in connection with Claybury.

The very difficulties - a striking and vivid reference to them is to be found in the Commissioners' Entry of October, I889-which in those days existed at 
Banstead by reason of its design and the types of patients that gradually had accumulated there, instead of an obstacle to him, proved educative and therefore of service; because quite early he began to make a practice of visiting other mental hospitals and of noting their facilities and learning their methods. Incidentally, it was at a visit which, in 1892 , he paid to the Royal Edinburgh Hospital at Morningside, that the writer of these remarks made his acquaintance, one that, owing to the accidental and exceptional circumstances of the visit, ripened into a friendship which eventuated in the latter's joining the Banstead staff after he had left and in their becoming colleagues at Bexley.

It is to be doubted if any other example can be found of a mental hospital physician of his standing-of his juniority, it would be more correct to say-so systematically devoting so large a share of annual leave to professional selfimprovement by the visiting of other mental hospitals ; in those days there were no Diplomas in Psychological Medicine. Commenced in his third year at Banstead by visits to several places in Scotland, in the autumn of the year to his appointment to Claybury he went to Germany largely for a like purpose. In the following year he obtained an extension of his annual leave with the object of visiting some representative mental hospitals (eight in all) in the eastern parts of the United States of America and, selecting four of them for description--St. Lawrence and Utica (New York), McLean (a division of the Massachuset ts General Hospital at Boston) and Toledo (Ohio)- -he was privileged to make a report (1894) upon them to the Asylums Committee of the London County Council which, with plans of each institution, was printed and circulated ; its date, December 24th (Christmas eve), is not without significance. In 1896 he again visited Germany and spent another holiday partly to refresh his memory of some hospitals he had seen previously, but especially to see the one at Alt-Scherbitz (Leipzig) and the Herzberge one for Berlin. On these, as well as upon two others for Berlin (Dalldorf and Biesdorf), together with observations on "Psychiatrical Clinics" either in connection with general hospitals (taking as an example the Charité Hospital in Berlin) or as forming part of a medical school (instancing that at Leipzig), he again had the privilege of submitting a report, this time to the Asylums Committee's special subcommittee on the Housing of the Insane; it also was printed and circulated. Earlier in the same year he had read a paper " Hospital Treatment of the Insane " before the Psychological Section of the British Medical Association at their July meeting at Carlisle.

There was no pigeon-holing of these reports; as it happened, there were at the time ears upon which their message fell with ready belief and response. Naturally, the post of Senior Assistant at Claybury, especially during the initial years of its opening, carried with it many privileges, of which Dr. Stansfield took full advantage; it is unquestionable that these reports and the opportunities he had of orally reinforcing the views in them not only greatly enhanced his position, but contributed largely to his appointment in July, 
I898, as the first Superintendent of Bexley Mental Hospital (Kent), the sixth for the County of London.

Foremost among the changes he urged were two pleas: First, the adoption of the cottage (or villa) system in the design of mental hospitals and the value of detached buildings unconnected by any corridor or covered way; in urging this system he expressed his astonishment at the hold which the then prevailing principle of a main building closely connected up with internal corridors had got on English architects, and he made a strong appeal to them to favour the cottage system on the score of economy and simplicity and to the doctors on the score of betterment in classification and administration. Second, the siting of such detached buildings so that recent cases-themselves adequately sub-divided-would be kept well separated from others. In the actual reports, though not in his later practice, he seems to have been rather puzzlingly content to leave convalescing cases among patients who, though well behaved, are of chronic types.

There were other matters which evidently he was quick to note, some of which he advocated, as, for instance, (i) the granting of parole and as much other liberty as practicable to industrious patients, and their housing in suitably sited villas; (ii) the use of spray-baths in lieu of the ordinary slipper ones (on which opinion is divided, but is mainly in favour of the latter); (iii) the greater extent (citing $80 \%$ of the total) to which patients could be employed - that is by adding to the number of utility occupations (methods by trained therapists were not envisaged); and (iv) greater liberality in number of the medical staff-at least twice that to be found in this country - with stenographers to help them, laboratories, and good medical libraries within the hospital. Others he was content to note without in terms advocating, as, for instance, (v) the considerable proportion of assistant physicians allowed to marry and provided with suitable accommodation-in which relation it is, however, of interest to record that it was at Bexley and within two years of his appointment as Superintendent that, for the first time in an English public mental hospital and much furthered by his support, a house was provided for a married deputy ; (vi) the extent of the grounds, twice and thrice that generally found here, with generous and bold lay-out of the buildings, the architect having been assisted by the services of a landscape-gardener, and with an absence of fear as to dangers from ornamental and recreational lakes; (vii) larger size (I26 square feet) for single-rooms, their windows fitted with unbreakable glass and without shutters; (viii) an absence at some places of padded rooms (his, considerably cut down in number and located with care, were used freely); and (ix) carefully organized service of meals from one central kitchen (a practice on which he later did not rely).

He described a system he had seen (at Dalldorf) of "boarding-out" of selected patients, the latter being brought back for inspection to the hospital monthly by their guardians, when the latter also received their pay. 
Though not with the same clarity and firmness of opinion as he gave to the various foregoing matters, he referred at some length to the existence of even then so-termed Psychiatric Clinics, either as part of general hospitals (as at the Charité Hospital in Berlin) or as part of a medical school (citing the one at Leipzig). It is doubtful if he visited any of them ; but he set out five reasons for advocating them. Three of these reasons, at any rate since the passing of the Mental Treatment Act, though still sound in themselves, no longer are dependent on such clinics; but two of his reasons, in so far as such a clinic might be part of the daily clinical life of a medical school, still hold goodfirst, the stimulus that would be given to the staff by having daily to teach ; and second, the diffusion of a better knowledge of psychological medicine throughout the medical profession, with corresponding earlier recognition and treatment and therefore enhanced progress.

In his reiterated advocacy of the cottage (or villa) system with abolition of corridors, he did not overlook the probability of opposition and that climatic conditions would be urged as a strong reason against its adoption in this country ; just as we indeed still hear from this or that corner of some county that the position is too exposed to permit any great use of an open verandah. It is characteristic of his shrewdness, of his forceful methods, and of the wisdom sometimes of meeting opposition before it is voiced that, in order to counter any such argument, he included in his report on German asylums a table of temperatures-mean, maximum, minimum, etc.-over a series of years at Berlin, Leipzig, and (for the previous fifty years) at Greenwich, which showed how practically identical the conditions were at these three places.

In concluding the second of these reports, and in cogent terms, Dr. Stansfield pointed out how well-fitted London was to take the lead and to adopt a forward policy in these matters. His plea was not in vain. At the eleventh hour, so to speak, and after the Bexley plans had received statutory approval, it was decided to add villas ; and, without doubt, this decision and its attendant discussion influenced Mr. Hine and Dr. Hayes Newington, who were intimately associated in the planning of the new mental hospital for East Sussex at Hellingly (opened in 1903) to include an admission hospital and some four villas in its original design. While a glance back to forty years ago has its definitely instructive value, the tentative and rather dubious way in which, not counting the little isolation hospital on standardized pattern, three detached buildings for patients were added to Bexley Hospital in the process of its erection incites a smile, especially in the light of subsequent wide extension in the use of detached buildings. Two were a pair, one on each side and obviously one for each sex, of two storeyed buildings, of quite simple but attractive, design with all the day space on the ground floor and the dormitories upstairs ; each possessed (as also did the third one) a small kitchen, scullery, etc., capable of cooking all the meals for its 35 patients. Neither why they were placed in the positions each occupied nor what function each was intended 
to serve did any one know ; and the same absence of knowledge applied to the third one, placed on the female side immediately outside and adjoining the ward-gardens at the end of the east and west central axis corridor and subway. The latter one was marked hospital ; it was for 50 patients, arranged in two identical wards of 25 beds each, one on the ground floor and one upstairs ; each ward was of the type then prevailing for sick and infirm cases, and neither had any special features. To those concerned with the gradual opening at Bexley, the pair of villas, so admirably suited as they obviously were for employed patients on parole, presented no doubt ; but it was only after much thought that decision was made to use the one designated hospital as the portal and initial treatment unit of every female patient admitted to Bexley; and so it remains. It was the first unit to serve solely that so important function at any public mental hospital in England. Had it and the other use of detached buildings proved a failure, it is possible that, in relation to the use of detached buildings and especially to the separate provision for recent cases, "the clock might have been set back" considerably. On the contrary, while Horton Mental Hospital was required so urgently that its plans were a re-duplication of those at Bexley and there was no opportunity to make modifications in either the siting or design of these detached units, a little later in the designing (1903) of Long-Grove (Epsom), in which Dr. Stansfield gave much valuable advice, a noteworthy step forward was taken both in the number of detached units provided (though by no means so big a one as he would have liked to take) and in the separation of recent from other cases ; and he had his way as to the distribution of these units. Also, he persuaded the architect (again, Mr. Hine) and the Committee entirely to dispense throughout the main building with closed corridors and to substitute instead either covered ways or corridors fully open on one side-an arrangement which never has been regretted.

Dr. Stansfield was twenty-three years (I898-I92I) Superintendent at Bexley ; full justice could not be done to his many activities there without access to the Hospital's records. It is easy, however, to recall the more salient ones. There was the further development of the villa system, including the use of parole, and of the separation of recent from other cases; the latter included the erection, in 1905, of an admission hospital for men, the design of which he largely inspired. The classification of patients throughout the whole hospital was on carefully considered lines and very strictly maintained. Great use was made of open-air treatment in bed on glass-roofed verandahs fully open in front. The nursing of some of the male sick-wards was placed under women nurses and under the Matron. Quite early and unrelated to more recent questions as to hours of duty of the nursing staff, Dr. Stansfield took much pains in elaborating a scheme approaching an eight-hour day which to some extent was put into operation. Arrangements were worked out whereby all industrious patients, those in wards as well as those on parole in villas, could 
be encouraged to sit up an hour or two later than the ordinary bedtime, which is apt so often to be irksomely early. Part of these arrangements included informal but much appreciated evening entertainments and parties in the wards. With the object of securing more appetizing and home-like meals, also to enable something in the way of a supper meal to be provided, the kitchen in each of the detached buildings was brought into full use and each villa was responsible for its own cooking - an arrangement which still is maintained. Diet-sheets were devised with the special object of permitting considerable choice, at the will of both patient and doctor, but by an elaboration of substitution columns a rigid prevention of waste was maintained. The general bathroom on each side was fitted entirely with spray-baths, the objects being economy, saving of time and ease of inspection.

Unacquainted with him in his youthful and formative years, this attempt to sketch his character must begin with his early professional years. Well and powerfully built, and well set-up; strong and good features, readily expressive, it might be of anger, but frequently of great kindliness, often enough of question or even of challenge; but the look, or rather gaze, was always alert, keen and virile. Slightly above average height, he looked taller, because he held himself well, had an air of command and self-confidence which seemed natural to him, and did, in fact, belong to a masterful nature. A slight but definite error in refraction of the right eye was corrected by a monocle, to some people the wearing of which is a blemish, but, in his case, it suited him so well as to seem almost part of him.

In the language of some psychologists, Stansfield was typically an extravert : dynamic, full of energy, not at all of the restless kind, but purposive and, though ready to grapple with any question or matter the day might bring forth, in general directed towards some clearly seen goal ; the obvious one, the one nearest at hand, and the one towards which his energies seemed directed in a very single-minded way was to make and to keep his hospital among the foremost of mental hospitals ; one, too, from which advice would tend to be sought and not in vain. It may be doubted, however, if that really was the limit of his horizon, but it is unquestionable that he was eminently successful in those efforts.

A trait deserves mention, not only as part of the portrait but because of the effect it undoubtedly exerted on others. Stansfield was no misogynist, not at all ; but, in the earlier half of his official life and despite a willingness to give his support towards the policy of providing houses for married officials, if not with regret it was with misgiving that he viewed the getting married or members of the staff; he feared, and indeed believed, that their devotion to their work, and in consequence its standard, would be impaired. This attitude was in fact part of his own single-minded devotion to his hospital, but perhaps more an expression of a curious and at times embarrassing "possessiveness" with which he seemed to surround those associated with him. 
Most happily for him the end of his own bachelor days was unexpectedly near. In 1908 he married Mary Caroline, daughter of the Hon. James Dever, of New Brunswick. Her influence awoke in him a healthy liking for many wider social activities; and, in the War, among her many and generous activities, Mrs. Stansfield organized a contingent of Boy Scouts of which her husband was President ; and Dr. Stansfield, to whom the rank of Lieut.-Col. R.A.M.C. was accorded, gave (I915-22) his services as Consultant for nervous and mental disorders to the Eastern Command, the high value of which was recognized by the conferment on him in I9I9 of the C.B.E.

To Col. Stansfield the changes of post-war years were irksome and he never fully reconciled himself to them. This fact and the growth of social claims decided him to retire soon after he had reached pensionable age, namely, in June, I92I, after slightly over thirty-one years service under the London County Council. Not that this implies that his medical interests had waned; for, besides papers in the Journal of Mental Science, in I III and I 913 and in the Lancet in I9I7, there had been a paper by him in the British Medical Journal as recently as I92I on "Causes of $\mathrm{C}_{3}$ Population"; and in that year, too, he was President of the Kent Branch of the British Medical Association. In the Council and Committee Minutes of April, May and June that year, record is made of his very special qualities as an administrator, of the always able and zealous manner in which his duties had been discharged, and of the valuable advice and assistance he had given in connection with the designing of new mental hospitals and in other directions.

On leaving Bexley, Col. and Mrs. Stansfield bought Southmead in Wimbledon, specially attracted by its gardens and their possibilities. In I 926 his wife died, and in 1928 he sold his house and bought Castello Devachan, a lovely place in San Remo, where he resided until the commencement of his fatal illness, for the treatment of which he had gone to Paris. In I929 he married Marie, second daughter of the late Alexander Efremoff, of Moscow, by whom he is survived. There were no children by either marriage.

The attempted tribute to the life and work of Col. Knowles Stansfield is by one who, among those of his fellow-workers still living, probably knew him longest, understood him best, and valued his worth not least. Maybe that, here and there, it contains words and phrases which others, though they would have scorned to flatter, would have omitted as savouring of adverse criticism. If so, their inclusion is, in fact, a further tribute to his teaching, to his insistence on the whole truth and an utter refusal to accept a partial or distortedly favourable account of any matter submitted to him. Let us remember that he had a great liking for roses and for tending them; and that " he who would grow roses must have them in his heart ".

HUBERT BOND. 